\section{Mammalian cell membranes}

Mammalian Cell Membranes. Vol. 4: Membranes and Cellular Functions. P.p. 262. Vol. 5: Responses of Plasma Membranes. Pp. 260. Edited by G. A. Jamieson and D. M. Robinson. (Butterworths: London and Boston, Massachusetts, 1977.) $£ 18$ each volume.

WITH these books, Jamieson and Robinson close the circle of their edited series on the structure and function of mammalian cell membranes. Volume 4 is concerned with ultrastructural, biochemical and physiological aspects. In the first chapter Deamer provides a brief account of freeze-etch images and an interpretation of intramembraneous particles. This is a useful companion to later discussions of the permeability of membranes by De Pont and Bonting, and of membrane action potentials by Carpenter.

The bulk of Volume 4 is concerned with functional aspects of cell surface membranes and receptor theory. The antigenicity of cell surfaces is well covered by Weiss and Klavins-in particular, the section on the structural relationships between CEA and blood group substances-although I was startled to see references to Feizi et al. (1900) on pp. 74 and 95 in view of the sensationally youthful appearance of Dr Ten Feizi of the Northwick Park Clinical Research Centre.

Surface immunoglobulins and the controversy of the T-cell receptor are dealt with admirably by Kern, and Edwards provides a succinct account of current thinking in cell adhesion. Ashwell summarises the present belief of many concerning the role of surface carbohydrates in recognition phenomena, including some of those appearing in Edwards' chapter. In addition to describing briefly his own classical experiments, Ashwell reminds us of the pioneering and still provocative work of the Gasics in the related area of cell surface carbohydrates and host responses to tumours.

Volume 5 is concerned with the way in which the external environment affects the cell surface membrane, and vice versa. The environment in the most fundamental sense includes the effects of hydrostatic pressure (Zimmerman and Zimmerman), water structure (Meryman) and radiations (Patrick) on membranes. At the other extreme of specificity, Birnbaumer et $a l$. make interesting sense of the huge literature on receptor coupling with adenyl cyclase, and on the regulation of the coupling by nucleotides. Strangely enough, the action of cholera toxin on membranes is not mentioned as a 'model' of hormone interactions with target cells.

In many biological processes, remodelling of cell surface membranes must occur. Several examples are considered in this volume, including endocytosis by Stockem, membrane fusion by Barski, membrane changes accompanying normal cell growth by Knox and Pasternak, and the senescent process by Robert. The best characterised of all remodelling processes, accompanying viral infection, is excellently treated by Klenk. The basic mechanisms by which membrane remodelling occurs is still a matter of speculation, although Scanlin and Glick clearly define the biochemical principles and dynamic nature of membrane turnover

\section{Strange compendium}

Handbook of Unusual Natural Phenomena. By William R. Corliss. Pp. 542. (The Sourcebook Project; Glen Arm, Maryland, 1977.) \$14.95.

WILlIAM CoRliss has been producing his 'sourcebooks' of such strange phenomena as ball lightning, plagues of frogs and miscellaneous phenomena associated with earthquakes since 1974. In the past, these have taken the form of loose-leaf folders containing synoptical accounts of observations reported in a wide variety of journals (with Nature prominent among them) and over a long period (back into the nineteenth century). The present 'handbook' presents the mixture as before but in more substantial and permanent form, as a bound volume of more than 500 pages, full of fascinating morsels.

The entries range in length from a couple of lines to a page or more plus diagrams, and cover in this volume

\section{Beat the machine}

Advances in Computer Chess. Edited by M. R. B. Clarke. Pp. 118. (Edinburgh University: Edinburgh, 1977.) $£ 3.50$.

IT is now many years since the electronic computer greatly exceeded the human brain in terms of speed and accuracy in calculation. But even in applications to well defined, finite games, such as chess, where this quality is at a premium, computers cannot match the performance of the more able human players.

This human advantage can largely be attributed to the possession of an ill-defined capability known as 'common sense', a concept unknown to computers. In the situation of the chess game, its activities are manifested in the human's ability to reject most of and discuss the concept of membrane flow.

I have now had the opportunity to read or browse through all five books of the series on Mammalian Cell Membranes and no doubt shall continue to profit from the immense amount of information therein for many years. The editors are to be congratulated on the success of their project, and they and their colleagues deserve our gratitude for providing a solid platform from which to view the rapidly changing membrane scene.

\section{R. C. Hughes}

R. C. Hughes is a member of the staff at the National Institute for Medical Research, London, UK.

phenomena grouped together as luminous phenomena, optical and radio anomalies, unusual weather phenomena, mysterious natural sounds, strange phenomena of earthquakes, phenomena of the hydrosphere and falling material. For anyone suffering from the delusion that science has reached a comforting state of explaining just about everything, the book may provide a few shocks; for the less sanguine among us, here is a delightful source of bed-time reading, full of anecdotes with which to amaze and amuse colleagues the next day. And, who knows, by reviving interest in such curiosities as the shower of sand eels reported by A. Meek in Nature (102, 46; 1918), Corliss may well encourage the development of an improved soientific understanding of some unusual natural phenomena.

John Gribbin

John Gribbin is a Visiting Fellow in the Science Policy Research Unit at the University of Sussex, UK.

the moves available to him as unworthy of analysis, and to analyse only those which are 'sensible'.

This book, consisting of a set of articles from a symposium held in Oxford in 1975 , deals with the problem of programming 'common sense' into a computer. In the chess context, this amounts principally to techniques of search reduction at the tactical level, and rudimentary 'planning' at the strategic level. A short article on the mathematical theory of search techniques, and several examples of the success (or lack of it) of practical programmes, complete a collection which should be worthwhile reading for those interested in the problems of machine intelligence.

\section{N. J. Holloway}

N. J. Holloway is Lecturer in the Astronomy Centre at the University of Sussex, UK. 